\title{
Heterogeneous snowpack response and snow drought occurrence across river basins of northwestern North America under $1.0^{\circ} \mathrm{C}$ to $4.0^{\circ} \mathrm{C}$ global warming
}

\author{
Rajesh R. Shrestha ${ }^{1}$ (D) Barrie R. Bonsal ${ }^{2} \cdot$ James M. Bonnyman $^{1}$ • \\ Alex J. Cannon ${ }^{3} \cdot$ Mohammad Reza Najafi $^{4}$
}

Received: 20 February 2020 / Accepted: 6 January 2021 / Published online: 12February 2021

(C) Crown 2021

\begin{abstract}
Anthropogenic climate change is affecting the snowpack freshwater storage, with socioeconomic and ecological impacts. We present an assessment of maximum snow water equivalent $\left(\mathrm{SWE}_{\max }\right)$ change in large river basins of the northwestern North America region using the Canadian Regional Climate Model 50-member ensemble under $1.0^{\circ} \mathrm{C}$ to $4.0{ }^{\circ} \mathrm{C}$ global warming thresholds above the pre-industrial period. The projections indicate steep $\mathrm{SWE}_{\max }$ decline in the warmer coastal/southern basins (i.e., Skeena, Fraser and Columbia), moderate decline in the milder interior basins (i.e., Peace, Athabasca and Saskatchewan), and either a small increase or decrease in the colder northern basins (i.e., Yukon, Peel, and Liard). A key factor for these spatial differences is the proximity of winter mean temperature to the freeze/melt threshold, with larger $\mathrm{SWE}_{\max }$ declines for the basins closer to the threshold. Using the random forests machine-learning model, we find that the $\mathrm{SWE}_{\max }$ change is primarily temperature controlled, especially for warmer basins. Further, under a categorical framework of below-normal $\mathrm{SWE}_{\max }$ defined as snow drought (SD), we find that above-normal temperature and precipitation are the dominant conditions for SD occurrences under higher global warming thresholds. This implies a limited capacity of precipitation increase to compensate the temperature-driven snowpack decline. Additionally, the frequency and severity of SD occurrences are projected to be most extreme in the southern basins where current water demands are highest. Overall, the results of this study, including insights on snowpack changes, their climatic controls, and the framework for SD classification, are applicable for basins spanning a range of hydro-climatological regimes.
\end{abstract}

Keywords Climatic controls · Global mean temperature change · Large ensemble RCM · Northwestern north america $\cdot$ Snow drought

Rajesh R. Shrestha

rajesh.shrestha@canada.ca

Extended author information available on the last page of the article 


\section{Introduction}

Snowpack provides a natural freshwater reservoir in snow-dominated regions of the world by storing precipitation in winter and releasing it as snowmelt runoff in spring and summer when demands are highest. Warming climate is causing significant alterations to snow regimes of the mountainous and high-latitude regions, affecting volume, extent, and duration of the seasonal snowpack, as well as snowmelt-driven runoff (Barnett et al. 2005; Bach et al. 2018). Studies have shown decreases in the duration and extent of snow cover (Brown and Mote 2009; Derksen et al. 2015; Mudryk et al. 2018) and declining trends in the mean and extreme snow depths (Fyfe et al., 2017; Bach et al., 2018; Mote et al., 2018), causing the snowmelt-driven peak runoffs to occur earlier (Dudley et al. 2017; Blöschl et al. 2017).

Associated with these changes are periodic occurrences of exceptionally low snow conditions, including recent occurrences in parts of the western USA (e.g., Mote et al. 2016; Cooper et al. 2016; Harpold et al. 2017; Hatchett and McEvoy 2017). These below-normal snow conditions relative to historical average maximum snow water equivalent $\left(\mathrm{SWE}_{\max }\right)$ or snow drought $(\mathrm{SD})$ have been characterized as dry $\mathrm{SD}$ due to winter precipitation deficit and warm SD due to above-normal winter temperature (Harpold et al. 2017; Dierauer et al. 2019). SD conditions could have substantial implications in regions where large populations rely on seasonal snowpack-driven runoff for water supply (e.g. for agriculture, human consumption, hydropower generation). Specifically, smaller snowpack and earlier snowmelt lead to earlier peak flow, increased winter flow, and decreased summer flow (Najafi et al. 2017). These changes could impact water availability, especially in regions where built reservoir capacity is inadequate to cope with the seasonal shifts in supply (Barnett et al. 2005), and lead to potentially large economic loss (Sturm et al. 2017). The decreasing contribution of snowmelt to runoff also makes streamflow less predictable and water management more challenging (Harpold et al. 2017). Additionally, natural ecosystems (e.g., vegetation, aquatic habitat) could be impacted, e.g., snowpack loss and earlier snowmelt have been associated with water stress on trees (Millar and Stephenson 2015) and increasing forest fire risks (Trujillo et al. 2012; Gergel et al. 2017). Furthermore, a decreasing contribution of snowmelt exacerbates stream warming during summer (Ficklin et al. 2013), which has been associated with elevated mortality of adult sockeye salmon (Eliason et al. 2011).

These issues are very relevant to the large region in northwestern North America (NWNA), where the majority of downstream flows originate from snowmelt runoff in "water towers" of the mountains (Bonsal et al. 2020). This large $\left(40^{\circ} \mathrm{N}\right.$ to $75^{\circ} \mathrm{N}$ and $100^{\circ} \mathrm{W}$ to $\left.160^{\circ} \mathrm{W}\right)$ region in Western Canada and the USA contains the trans-boundary river basins of Yukon, Mackenzie, Saskatchewan, Fraser, and Columbia, and parts of the region have been characterized as "at risk" of transitioning from a snow-dominated to a rain-dominated winter precipitation regime (Nolin and Daly 2006; Brown and Mote 2009). Furthermore, environmental and freshwater demands/pressures are prevalent across the region, especially in more southern river basins with higher population and infrastructure demand (Bonsal et al. 2020). Previous studies indicated declining trends of multidecadal snow water equivalent (SWE) in parts of the region, which have been attributed to anthropogenic forcings (Pierce et al. 2008; Najafi et al. 2017). Future climate projections over NWNA indicate a continuation of historical trends, i.e., declines in the magnitude, extent and duration of snow storage due to warming temperatures (e.g., Diffenbaugh et al. 2013; Fyfe et al. 2017). 
However, highly spatially varied climatology (Fig. 1) together with differences in temperature and precipitation projections across mid- to high-latitude regions suggests heterogeneous snowpack responses in the river basins of the region. Specifically, enhanced warming at higher latitudes, coupled with amplified poleward moisture transport (Min et al., 2008; Zhang et al., 2013) - referred to as the Arctic amplification (Serreze and Barry 2011; Cohen et al. 2014) can be expected to lead to latitudinally varied snow responses across NWNA. The changes could include a larger decrease in mean snowfall at mid-latitudes compared to high latitudes (O'Gorman 2014) and a higher prevalence of low snow years at mid-latitudes (Diffenbaugh et al. 2013). Also relevant is the temperature gradient across NWNA, with the mid-latitude region's winter temperatures, at present, closer to the freeze/melt threshold than high latitudes (Fig. 1a). This suggests a higher sensitivity of the mid-latitude region's snow regime to climate warming and increased sensitivities at higher latitudes as the threshold shifts northward. In this respect, while a number of previous studies have analyzed future snowpack changes across the mid-latitudes (Fyfe et al. 2017; Dierauer et al. 2019), the spatial and temporal variability of snowpack changes across the major river basins of this large region has not been investigated. Such investigation can be helpful in characterizing second/third-order impacts, including water supply, storage and ecosystem services, and thus, future adaptation strategies for these important river basins in NWNA. Further, with the release of the Intergovernmental Panel on Climate Change (IPCC) special report on Global Warming of $1.5{ }^{\circ} \mathrm{C}$ (IPCC 2018), understanding basin-scale impacts at different policy-relevant goals (e.g., limiting global warming to $1.5^{\circ} \mathrm{C}$ or $2.0^{\circ} \mathrm{C}$ ) has become important.

Given the aforementioned knowledge gaps, the objective of this study is evaluating large basin-scale snowpack response over the NWNA region. We develop a framework for assessing the climatic controls on $\mathrm{SWE}_{\max }$ responses and evaluating $\mathrm{SD}$ occurrences in a warmer climate. We focus on two key research questions: (i) how do the climatic controls on snow response vary across the river basins with a range of hydro-climatological regimes? (ii) How does the frequency and severity of snow drought vary under different global warming thresholds $\left(1.0^{\circ} \mathrm{C}\right.$ to $4.0^{\circ} \mathrm{C}$ above the pre-industrial period)? To address these questions, we primarily utilize a large ensemble (50 realizations) of the Canadian Regional Climate Model (CanRCM4-LE) (Scinocca et al. 2015), driven by historical and future simulations from the Canadian Earth System Model (CanESM2) (Arora et al. 2011). We apply a machine-learning model, random forests (Breiman 2001), to evaluate the relative importance of primary climatic
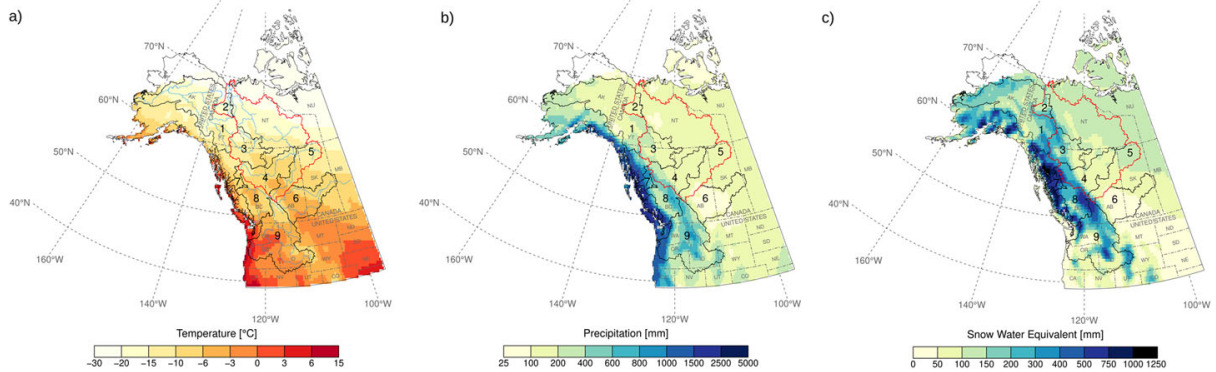

Fig. 1 Baseline climatology (1961-2000) from CanRCM4-LE mean for the study region relevant to snow accumulation and melt season. a October-March mean temperature. b October-March total precipitation. c Annual maximum SWE. Numbers indicate nine river basins studied in detail: 1 Yukon, 2 Peel, 3 Liard, 4 Peace, 5 Athabasca, 6 Saskatchewan, 7 Skeena, 8 Fraser, and 9 Columbia. Mackenzie basin is shown by the red boundary. Note that CanRCM4-LE extends approximately to the northern boundary of the Yukon River basin 
drivers (temperature and precipitation) on $\mathrm{SWE}_{\max }$ response. Further, we define $\mathrm{SD}$ based on categorical classifications (i.e., above-normal, near-normal and below-normal) of temperature, precipitation, and snow conditions. Additionally, a detailed basin-scale prognosis of $\mathrm{SWE}_{\max }$ changes and SD occurrences is provided under $1.0{ }^{\circ} \mathrm{C}$ to $4.0^{\circ} \mathrm{C}$ global warming.

\section{Study region}

Our study foci are the large river basins that originate in the Canadian portion of the NWNA region (Fig. 1) and includes four major tributaries of the Mackenzie River (Peel, Liard, Peace, and Athabasca), along with the entire Yukon, Skeena, Saskatchewan, Fraser, and Columbia River basins (see Supplementary Material (SM) Table S1 for basin characteristics). Climatic regimes of the region range from subarctic in the north to temperate in the south. The region is highly varied in terms of temperature and precipitation, with a distinct temperature gradient from south to north and precipitation gradient from interior to coast (Fig. $1 \mathrm{a}$ and $\mathrm{b}$ ). The resulting $\mathrm{SWE}_{\max }$ response generally corresponds to October-March precipitation, with higher accumulation in the coast compared to interior (Fig. 1c). However, despite higher precipitation, $\mathrm{SWE}_{\max }$ values are lower in the southern coast due to above freezing October-March temperature.

The selected river basins are highly diverse in terms of water usage, thus, subject to different levels of vulnerabilities. Particularly, the southern basins of Fraser, Columbia, and Saskatchewan - which are home to large populations in Western Canada including the major urban centers of Vancouver, Edmonton, and Calgary-have considerable demand for drinking water, irrigation, and hydropower generation. Particularly, hydropower generated from the Columbia River supplies about $77 \%$ of the regional demand for electricity inside the basin in the USA and Canada (Hamlet et al. 2002), while about $22 \%$ of flow is diverted from Saskatchewan River for consumptive water use, mainly for irrigation (Bruneau et al. 2009). Parts of the region, including Greater Vancouver and Calgary, are vulnerable to flooding, which occur due to snowmelt-driven runoff in combination with heavy rainfall events (Pomeroy et al. 2016; Shrestha et al. 2017). There are major hydropower generation and oil-sand development in the Peace and Athabasca River basins, respectively, with both highly dependent on snowmelt-driven runoff (Schnorbus et al. 2014; Dibike et al. 2018). The northern region (including the Yukon, Peel, and Liard basins) has a sparse population and limited development. However, snowpack loss together with permafrost degradation could have major implications on infrastructure and services (Instanes et al. 2016). Further, river systems draining to the coast, including Fraser and Skeena, provide important spawning habitat for Pacific Salmon (Morrison et al. 2002; Beacham et al. 2014) and are highly sensitive to summer water temperature increases (Eliason et al. 2011).

\section{Data and methods}

\subsection{Model datasets}

This study is primarily based on the large ensemble $0.44^{\circ}$ CanRCM4 (CanRCM4-LE), a regional climate model that was developed under the framework of coordinated global and 
regional climate modeling (Scinocca et al. 2015). CanRCM4 shares the same package of physical parameterizations with the Canadian global atmospheric climate model (CanAM4) (Von Salzen et al. 2013). By employing a spectral nudging procedure in the Canadian Earth System Model (CanESM2) (Arora et al. 2011), which is designed to constrain its evolution to follow any large-scale driving data, CanRCM4 is supplied at the lateral boundary with inputs from its parent GCM (Scinocca et al. 2015). CanRCM4 also includes the Canadian Land Surface Scheme (CLASS) version 2.7, which has been designed from the outset to account for snowpack dynamics (Verseghy 2000; Bartlett et al. 2006). Specific features of CLASS relevant to snowpack dynamics include a variable depth snow layer and snow-vegetation interactions for water and energy flux calculations. CLASS considers canopy snow interception in terms of variable leaf area index, while snowpack albedo and density vary with time, depth, temperature, and new snow according to an exponential decay function. Further details on CLASS snow model are available in Verseghy (2000) and Bartlett et al. (2006).

The 50-member $0.44^{\circ}$ CanRCM4-LE simulations over the North American domain are driven at the boundary by CanESM2, with forcings from Coupled Model Intercomparison Project Phase 5 (CMIP5) (Taylor et al. 2012) historical and representative concentration pathway 8.5 (RCP8.5). The CanRCM4-LE runs were set up by initializing with five CanESM2 historical simulations and randomly perturbing the initial conditions in the year 1950 and performing 10 runs for each CMIP5 ensemble member (Kirchmeier-Young et al. 2017). CanRCM4-LE has also been used by Fyfe et al. (2017) for the projection of near-term snow response in the western USA.

Given the mountainous topography of the NWNA region, the $0.44^{\circ}$ CanRCM4 (approximately $50 \times 50 \mathrm{~km}^{2}$ ) can be expected to result in elevation-dependent biases, especially when considering grid-scale responses. Nevertheless, we used CanRCM4-LE because of the limited availability of higher-resolution simulations covering the entire region. Furthermore, since our analyses are based on basin-averaged responses (drainage areas: $57,000 \mathrm{~km}^{2}$ to $850,000 \mathrm{~km}^{2}$; SM Table S1), the grid-scale uncertainty is assumed less critical. In addition, large ensemble simulations (such as CanRCM4-LE) allow the consideration of a climate model's internal variability, and an amplitude of natural climate variability (Kay et al. 2015). As emphasized by Deser et al. (2020), the consideration of internal variability is important because it is an intrinsic property of a model and largely irreducible, and could account for a large fraction of the CMIP5 GCMs inter-model spread. We also compared the CanRCM4 projections with $0.22^{\circ} \mathrm{RCM}$-ensemble that comprise a single-member CanRCM4 and 3-member REMO RCM (Jacob et al. 2012), and variable infiltration capacity (VIC) hydrologic model simulations for the Liard, Peace, and Fraser basins (Shrestha et al. 2012, 2019; Schnorbus et al. 2014) (see SM section $\mathrm{S} 2$ ).

\subsection{Global mean temperature change calculation}

We considered SWE, temperature, and precipitation changes under the policy-relevant thresholds of $1.0^{\circ} \mathrm{C}, 1.5{ }^{\circ} \mathrm{C}, 2.0{ }^{\circ} \mathrm{C}, 3.0^{\circ} \mathrm{C}$, and $4.0^{\circ} \mathrm{C}$ global mean temperature (GMT) changes with respect to the pre-industrial (PI) period of 1850-1900 following IPCC (2018). Given that GCMs have different levels of climate sensitivities and biases, and respond differently to the same radiative forcing scenario (Schleussner et al. 2016), the periods of GMT changes are different for each GCM. In this study, the GMT changes for CanRCM4 were taken from Jeong et al. (2019), in which the 31-year period of each GMT change was calculated relative to 
1986-2005, with a $0.79{ }^{\circ} \mathrm{C}$ temperature increase for the driving CanESM2 considered between the PI period and 1986-2005 (SM Table S2). Since CanRCM4 simulations are not available for the PI period, basin-scale comparisons of temperature, precipitation, and SWE changes at different GMT levels were carried out with respect to the more recent baseline period of 19612000 .

\subsection{Variable importance analysis}

Following previous regression-based studies, which found high sensitivities of snow to seasonal precipitation and temperature (e.g., Luce et al. 2014; Lute and Luce 2017; Sospedra-Alfonso and Merryfield 2017), we evaluated the relative importance of these primary climatic drivers (air temperature and precipitation corresponding to snow accumulation and melt season) on snowpack response. We used the random forest (RF) ensemble machine learning method for the predictor-response variable importance (VI) analysis because of its ability to handle complex nonlinear problems including interactions between variables (Breiman 2001), which is an important consideration given that the snow response is a result of temperature and precipitation interactions. RFs have also been found to be efficient on large databases (Wang et al. 2015) and provide reasonable estimation of VI, e.g. for identification of climatic controls on snow and streamflow responses (Shrestha et al. 2019) and evaluation of indices that contribute to flood hazard (Wang et al. 2015). See Breiman (2001) and Liaw \& Wiener (2002) for technical details on RF.

This study employed the "randomForest" R-package (Liaw and Wiener 2018) to setup a separate RF model for each of the nine river basins. We used the RF model to evaluate the basinaveraged annual maximum SWE ( $\mathrm{SWE}_{\max }$ ) response as a function of snow season air temperature (herein referred to as temperature) and precipitation, i.e., October-December (OND) and January-March (JFM) temperature (T) and precipitation (P). The RF model inputs included four variables, i.e., OND_T, OND_P, JFM_T, JFM_P and one output variable, i.e., SWE $\max$, with anomalies of each variable relative to 1961-2000 used to assess the effects of temperature and precipitation changes on $\mathrm{SWE}_{\max }$ changes. In order to analyze VI covering the entire period of 1961-2100, all 50 ensemble members of CanRCM4-LE with a combined total of 7000 model years ( 50 simulations $\times 140$ years) were used for training the RF model. The predictability of the response variable was assessed using the Nash-Sutcliffe coefficient of efficiency (NSE).

\subsection{Snow drought characterization}

We used a categorical framework, consisting of a combination of temperature, precipitation, and $\mathrm{SWE}_{\max }$ quantiles at the above-normal, near-normal, and below-normal classes for evaluating the SD conditions. We divided the quantiles relative to the categorical tercile boundaries of the baseline period (1961-2000): (i) <33rd percentile as below-normal; (ii) between the 33rd and 67th percentiles as near-normal; and (iii) $>67$ th percentile as abovenormal. The classification is analogous to the probabilistic climate forecasting in which shifts in forecasts (e.g., precipitation and temperature) are stipulated against the historical climatological distribution (Barnston \& Tippett, 2014). We defined (i) below-normal SWE $\mathrm{max}_{\text {ax }}$ conditions as SD; thus, SD occurs $33 \%$ of the time in the baseline climate and no-change future condition. The 33rd percentile threshold lies between the climatological mean threshold in Dierauer et al. (2019) and consecutive years of $\mathrm{SWE}_{\max }<25$ th percentile in Marshall et al. (2019). 
We propose a generalized SD definition, applicable to primary mechanisms of SD occurrences in a range of hydro-climatic regimes, and in both historical and future climates (SM Fig. $\mathrm{S} 1)$. Given that SD could occur under both precipitation and temperature increases in a warmer climate, we expanded the SD classifications by Harpold et al. (2017) and Dierauer et al. (2019) to include the potential drought types. Accordingly, three main SD classes were identified:

$$
\begin{gathered}
\left\{\left(S W E_{\text {max }, i}<S W E_{\text {max }, 33}\right) \wedge\left(P_{i}<P_{33}\right) \wedge\left(T_{i}>T_{67}\right)\right\} \rightarrow S D_{\text {warm }+ \text { dry }} \\
\left\{\left(S W E_{\text {max }, i}<S W E_{\text {max }, 33}\right) \wedge\left(P_{33}<P_{i}<P_{67}\right) \wedge\left(T_{i}>T_{67}\right)\right\} \rightarrow S D_{\text {warm }} \\
\left\{\left(S W E_{\text {max }, i}<S W E_{\text {max }, 33}\right) \wedge\left(P_{i}>P_{67}\right) \wedge\left(T_{i}>T_{67}\right)\right\} \rightarrow S D_{\text {warm }+ \text { wet }}
\end{gathered}
$$

where $S W E_{\max , i}, P_{i}$, and $T_{i}$ are the basin-averaged maximum SWE, and October-March precipitation and temperature, respectively, in year $i . S W E_{\max , 33}, P_{33}$, and $T_{33}$ are the 33rd percentiles of $S W E_{\max }$ and October-March precipitation and temperature for the baseline period (1961-2000), respectively. Likewise, $P_{67}, T_{67}$ are the 67th percentiles of the October-March precipitation and temperature for the baseline period, respectively. Besides, these three SD classes decrease in $S W E_{\max }$ could occur under other conditions, especially below-normal precipitation (e.g., dry and cold + dry classes; SM Fig. 1). However, SD occurrences under these conditions were found to be rare in our evaluation of future response and were not considered.

\section{Results and discussion}

\subsection{Future snow response under GMT change}

The CanRCM4-LE temperature projections at $1.0{ }^{\circ} \mathrm{C}$ to $4.0{ }^{\circ} \mathrm{C}$ GMT change thresholds indicate progressively higher warming with GMT increases, which is consistent with the expectation of enhanced warming in the northern latitudes. Projected precipitation changes are highly heterogeneous, with larger increases in the northern region and southern interior, and progressively larger changes at higher GMTs (see SM Figs. S2 and S3). The signal-tonoise ratios of temperature and precipitation changes - as represented by the ensemble mean divided by standard deviation of the 50-member model simulations - are greater than one in most areas, with the exception of precipitation changes at $1.0^{\circ} \mathrm{C}$ and $1.5^{\circ} \mathrm{C}$ warmings in the southern parts. Thus, in most cases, the change signals arising from the GMT increases are beyond the range of CanRCM4-LE internal variability. This also suggests that the strengths of temperature and precipitation increase signals are robust across the domain, even at low GMT increases.

In the case of $\mathrm{SWE}_{\max }$, the responses are spatially heterogeneous, with a general pattern of increases in the northern region and declines in the southern and coastal regions (Fig. 2). These results are in general agreement with the $\mathrm{SWE}_{\max }$ trends over 2020-2050 using CMIP5 GCM ensemble (Mudryk et al. 2018). At $1.0^{\circ} \mathrm{C}$ GMT change, the region approximately north of $60^{\circ}$ $\mathrm{N}$ show increases in $\mathrm{SWE}_{\max }$, except for the Alaska coast areas where temperature increases are higher (SM Fig. S2), while south of $60^{\circ} \mathrm{N}$ show decreases. Besides this north to south 
gradient, there is also an interior region to coast gradient of decreasing $\mathrm{SWE}_{\max }$. With the GMT increases from $1.5^{\circ} \mathrm{C}$ to $4.0^{\circ} \mathrm{C}$, the patterns of change are amplified, characterized by progressively larger snow losses in the southern region, more intense losses in the coast, and progressively larger increases in the northernmost region, while the areas with $\mathrm{SWE}_{\max }$ losses expand. Further, the $\mathrm{SWE}_{\max }$ results at low GMT changes (i.e., $1.0{ }^{\circ} \mathrm{C}$ to $1.5{ }^{\circ} \mathrm{C}$ ) are characterized by strong loss signals (signal-to-noise ratios $>1$ ) in the southern and coastal regions, and relatively weak increased signals (signal-to-noise ratios $<1$ ) in the northern region. At $2.0{ }^{\circ} \mathrm{C}$ to $4.0{ }^{\circ} \mathrm{C}$ GMT increases, the change signals are strong across most of the domain, with highly heterogeneous patterns of $\mathrm{SWE}_{\max }$ declines in the south and increases in the north, and weak signals in small transition areas.

Also relevant to $\mathrm{SWE}_{\max }$ changes are the basin-scale winter temperature states. For instance, Lute and Luce (2017) found April 1 SWE to winter precipitation ratios vary between $\sim 1$ and 0 in areas with $-8{ }^{\circ} \mathrm{C}$ to $+4{ }^{\circ} \mathrm{C}$ variations in winter temperatures. In this study, the $\mathrm{SWE}_{\max }$ changes in the three northern basins (Yukon, Peel, and Liard) are small, because the basins will remain cold even under more intense warming (Fig. 3), and the temperature-driven reduction in snowfall fraction is mostly compensated by increased precipitation (SM Fig. S3). For the three interior basins (Peace, Athabasca, and Saskatchewan), such balance between basin temperature and precipitation increases seem to mostly maintain the historical $\mathrm{SWE}_{\max }$ levels up to $2.0{ }^{\circ} \mathrm{C}$ warming. However, at $3.0^{\circ} \mathrm{C}$ and $4.0^{\circ} \mathrm{C}$ warmings, it is apparent that the balance is no longer maintained and substantial loss in $\mathrm{SWE}_{\max }$ occurs. In the case of three coastal/southern basins (Skeena, Fraser, and Columbia), rapid declines in the $\mathrm{SWE}_{\max }$ start at $1.5{ }^{\circ} \mathrm{C}$ GMT increase due to the proximity of the basin temperatures to the freeze/melt threshold. Overall, a rapid $\mathrm{SWE}_{\max }$ loss in the region seems to occur when the mean basin October-March temperature goes above $-5.0^{\circ} \mathrm{C}$ to $-6.0^{\circ} \mathrm{C}$. Rapid loss was also projected by Fyfe et al. (2017) in their evaluation of near-term (2013-2033) $\mathrm{SWE}_{\max }$ change over the

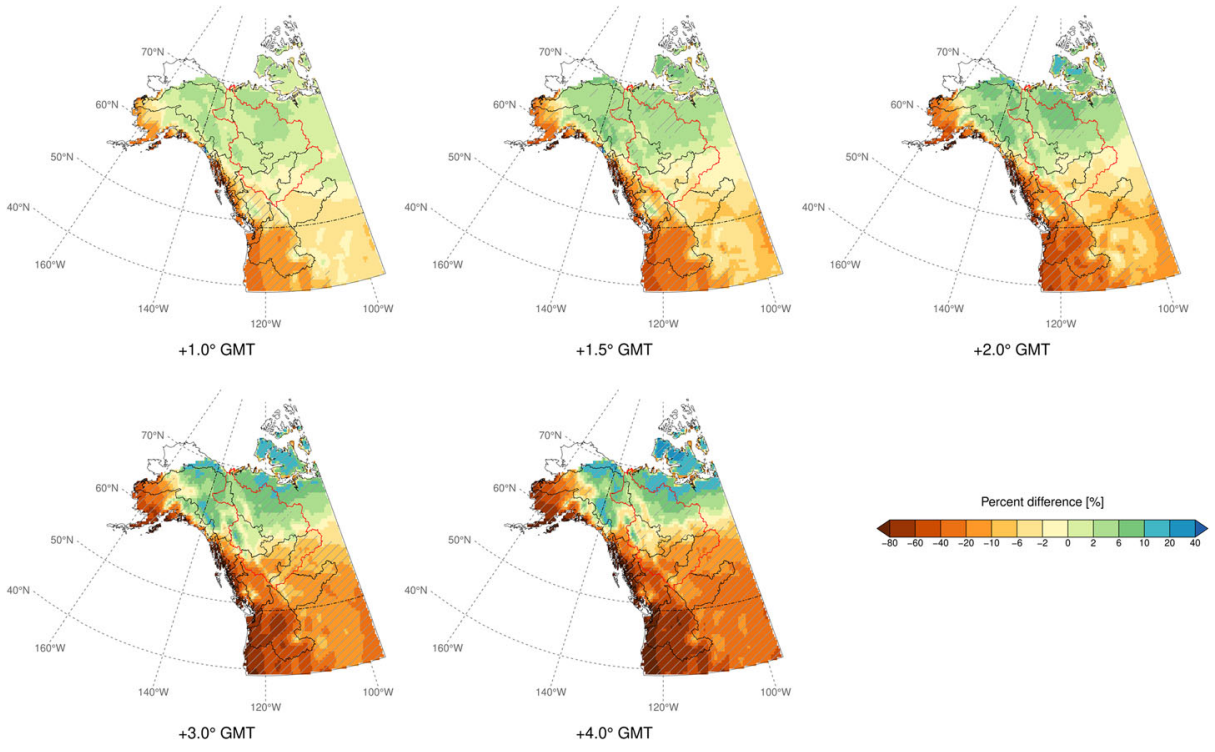

Fig. 2 Projected changes in $\mathrm{SWE}_{\max }$ under the GMT changes from $1.0{ }^{\circ} \mathrm{C}$ to $4.0{ }^{\circ} \mathrm{C}$, relative to the mean of baseline period 1961-2000. Hatching indicates areas where the mean of 50-member CanRCM4-LE divided by standard deviation is greater than 1 
Western USA. Further, these results are in general agreement with previous studies that found relatively larger snowpack declines at lower elevations than higher elevations, and by extension larger declines at higher basin temperatures (e.g., Cooper et al. 2016; Gergel et al. 2017; Huning and AghaKouchak 2018; Marshall et al. 2019). However, the changes cannot be fully explained in terms of mean basin temperatures. For instance, although the basin temperatures are similar in Skeena, Fraser and Saskatchewan, the $\mathrm{SWE}_{\max }$ reduction in the former two is more amplified between $1.5{ }^{\circ} \mathrm{C}$ and $4.0^{\circ} \mathrm{C}$ GMT compared to the latter.

\subsection{Variable importance of snow changes}

Figure 4 summarizes the VI percentage scores obtained from the RF model for the nine basins, with the relative controls of CanRCM4-LE simulated OND and JFM temperature and precipitation changes on $\mathrm{SWE}_{\max }$ changes depicted. The controls vary greatly across the NWNA region, characterized by decreasing influence of precipitation and increasing influence of temperature from northern (colder) to southern (warmer) basins. Specifically, while precipitation exerts the highest influence on $\mathrm{SWE}_{\max }$ in the northernmost and coldest Peel basin, there is only a minor influence of OND and JFM precipitation $(\mathrm{VI}<10 \%)$ on the coastal/southern (Skeena, Fraser and Columbia) basins. Overall, the temperature control on the southernmost basin (Columbia) is about three times higher than the northernmost basin (Peel), with progressively higher sensitivities from north to south. Furthermore, there are differences in the seasonal temperature controls on $\mathrm{SWE}_{\max }$, e.g., higher influence of $\mathrm{OND}_{-} \mathrm{T}$ for the three
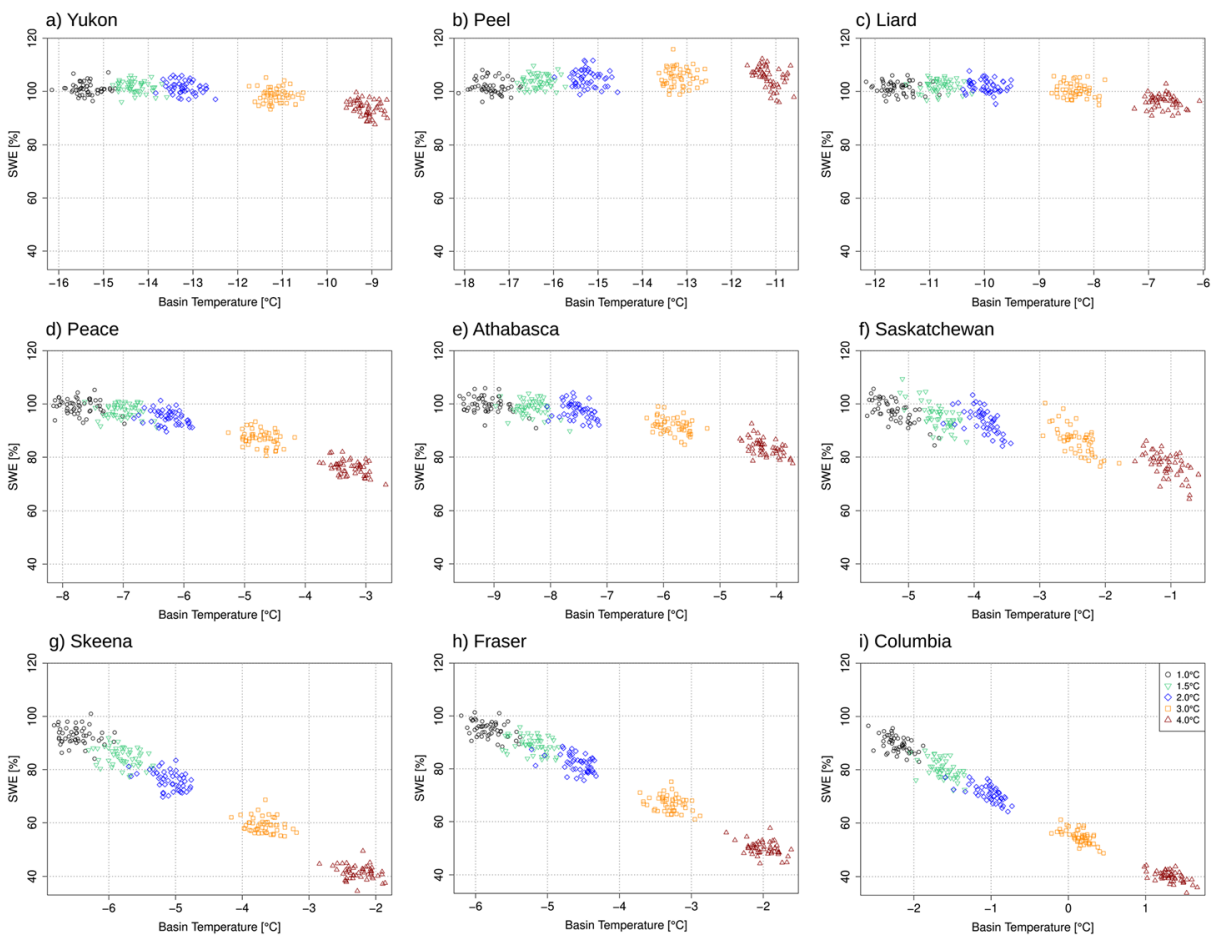

Fig. 3 Changes in mean $\mathrm{SWE}_{\max }$ relative to October-March mean basin temperatures, under $1.0^{\circ} \mathrm{C}$ to $4.0^{\circ} \mathrm{C}$ GMT changes. The results depict 31-year means from 50-member CanRCM4-LE, and the changes are considered relative to the mean of 1961-2000 baseline period 
northern basins (Yukon, Peel, Liard) and two interior basins (Peace, Athabasca) and higher influence of JFM_T for the coastal/southern basins (Saskatchewan, Skeena, Fraser, Columbia). Possible reasons for these differences include the temperature influence on the start of snow accumulation, snowmelt initiation, and distribution of seasonal snowfall. Further, as explained earlier, the snow accumulation/melt season (October-March) basin temperature state plays an important role on snowpack response and its change (Fig. 3). In general, the warmer the basin temperature state, the higher is the temperature control on $\mathrm{SWE}_{\max }$, and the smaller is the influence of precipitation on $\mathrm{SWE}_{\max }$ change.

The RF model predictability scores, summarized in terms of NSE values, indicate moderate (0.4 to 0.6$)$ to good $(>0.6)$ model fits. Comparing the colder northern basins to warmer southern basins, the NSE values are higher with the predominant temperature controls in the south. Further, given the high NSE values $(>0.8)$, the decline in $\mathrm{SWE}_{\max }$ storage in the Skeena, Fraser, and Columbia basins can be mostly explained by seasonal temperature increases. The NSE values are lower for the northern basin, especially Peel and Liard, thus, the seasonal temperature and precipitation changes do not sufficiently explain the $\mathrm{SWE}_{\max }$ change. The NSE-based performance also suggests a potential for developing predictive snowpack models using RFs, with further decomposition of driving variables (e.g., rainfall and snowfall) and model selection using different metrics offering possible pathways for further improvements (e.g., Räisänen 2008; Lute and Luce 2017). This was not explored in this study since we are only focused on VI of precipitation and temperature on $\mathrm{SWE}_{\max }$ response.

Further, we analyzed the sensitivities of $\mathrm{SWE}_{\max }$ in relationship to October to March temperature and precipitation changes, and at $1.0{ }^{\circ} \mathrm{C}$ to $4.0{ }^{\circ} \mathrm{C}$ GMT changes for the nine selected basins (Fig. 5). The results depict contrasting responses to temperature and precipitation changes, characterized by increasing sensitivities of $\mathrm{SWE}_{\max }$ from north to south. Specifically, while $\mathrm{SWE}_{\max }$ generally declines with GMT increases, the magnitude of changes varies across the region, i.e., small reductions under higher $\left(4.0^{\circ} \mathrm{C}\right)$ GMT change in the northern basins (Yukon and Liard), moderate declines ( $\sim 90 \%$ remaining at $2.0{ }^{\circ} \mathrm{C}$ and $\sim 80 \%$

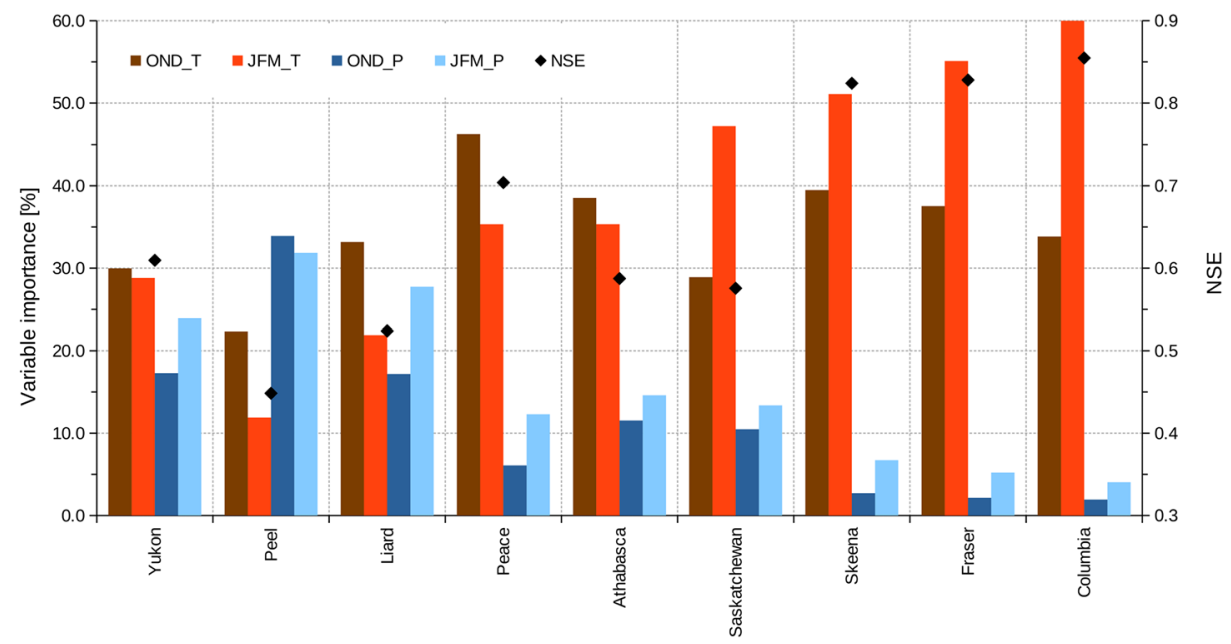

Fig. 4 Variable importance scores $(\%)$ for $\mathrm{SWE}_{\max }$ change with respect to October-December and JanuaryMarch temperature and precipitation changes for nine river basins. Also shown are the model fits in terms of NSE 
remaining at $4.0^{\circ} \mathrm{C}$ ) in the interior (Peace, Athabasca and Saskatchewan), and steep declines $\left(\sim 80 \%\right.$ remaining at $2.0^{\circ} \mathrm{C}$ and $\sim 40 \%$ remaining at $4.0{ }^{\circ} \mathrm{C}$ ) in the coastal/southern basins (Skeena, Fraser, Columbia). As outlined earlier, the large $\mathrm{SWE}_{\max }$ reductions in the southern basins correspond to higher temperature sensitivities (Fig. 4), which in turn can be linked to the near-freezing October-March temperatures in these basins (Fig. 3). Further, it is evident that the precipitation increase is not able to offset the warming-induced decline in snow accumulation. In contrast, in the relatively colder northern basins, the higher precipitation increases mostly sustain the baseline $\mathrm{SWE}_{\max }$ levels even with higher temperature increases. The importance of the basin-scale temperature on future $\mathrm{SWE}_{\max }$ response is illustrated by contrasting responses between (b) Peel and (f) Saskatchewan basins. While the precipitation increases for the two basins are in the similar ranges, there are more pronounced declines in $\mathrm{SWE}_{\max }$ in the warmer Saskatchewan basin even with smaller temperature increases. Nevertheless, the basin-scale precipitation change does have a role in $\mathrm{SWE}_{\max }$ change. For instance, comparing the (f) Saskatchewan and (g) Skeena basins, where temperature changes and historical temperature ranges are similar, there is a smaller $\mathrm{SWE}_{\max }$ decline in Saskatchewan due to larger precipitation increase. Overall, under the warming scenarios, the basins with higher temperature sensitivities will experience more substantive snow declines than the basins with higher precipitation sensitivities, with the magnitude of precipitation increase determining the magnitude of $\mathrm{SWE}_{\max }$ change.

The higher $\mathrm{SWE}_{\max }$ sensitivity to winter temperature for the warmer coastal/southern basins is consistent with the observation-based spatial analog of snowpack response in the western USA (Lute and Luce, 2017), where April 1 SWE to precipitation ratio tended to decline rapidly with warmer temperatures compared to colder temperatures. Furthermore, the results of this study align with the northern hemisphere snowpack variability assessment by Sospedra-Alfonso and Merryfield (2017). Using CanESM2 1850-2100 simulations, they found a threshold of $-5 \pm 1{ }^{\circ} \mathrm{C}$, below which the snowpack amount is primarily driven by precipitation and above which it is primarily driven by temperature. The threshold also aligns well with the start of the rapid snowpack decline in this study (Fig. 3). Thus, with the twenty-first century warming, sensitivity of snowpack response to temperature in warmer regions increases and even dominates, likely due to temperature-induced reduction of the snowfall fraction, which is not compensated by precipitation increases. Additionally, the regions currently with higher precipitation sensitivity would be expected to become more sensitive to temperature.

\subsection{Changes in snow drought characteristics}

Next, we compared the quantiles of 50-member CanRCM4-LE spatially averaged $\mathrm{SWE}_{\max }$ under the scenarios of $1.0{ }^{\circ} \mathrm{C}$ to $4.0{ }^{\circ} \mathrm{C}$ GMT changes (Fig. 6). Corresponding to the SD definition, the $\mathrm{SWE}_{\max }$ values were normalized by the $33 \mathrm{rd}$ percentiles of the baseline period (1961-2000). Thus, values below the normalized $\mathrm{SWE}_{\max }=1$ (shown by a vertical line) indicate SD conditions, while values between 33rd and 67th percentiles (shown by the second vertical line) indicate near-normal snow conditions. The results generally reveal a consistent pattern in terms of the direction of change, i.e., shift toward lower $\mathrm{SWE}_{\max }$ values with higher levels of warming. An exception is the Peel basin, where small shifts toward higher $\mathrm{SWE}_{\max }$ values are projected under higher warming thresholds. The difference can be mainly attributed to the predominant precipitation control for this basin (Fig. 4), with the effects of precipitation increases overshadowing the effects of warming. In the case of Yukon and Liard basins, there 

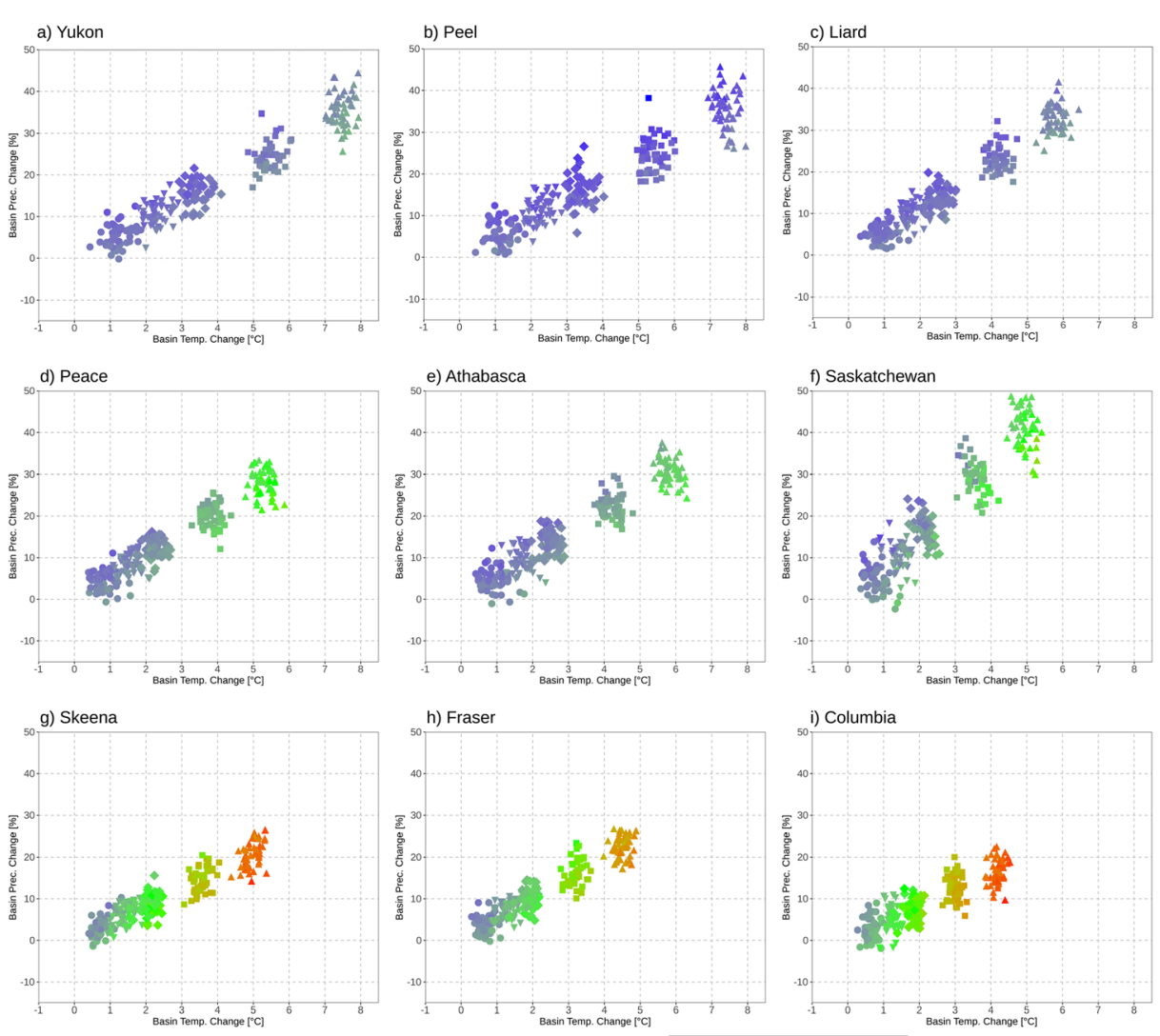

$\begin{array}{lccccccc}40 & 50 & 60 & 70 & 80 & 90 & 100 & 110 \\ & \text { Fraction of SWE } & \text { remaining }\end{array}$

- $1.0^{\circ} \mathrm{C} \nabla 1.5^{\circ} \mathrm{C}+2.0^{\circ} \mathrm{C} \boldsymbol{\|} 3.0^{\circ} \mathrm{C} \Delta 4.0^{\circ} \mathrm{C}$

Fig. 5 Sensitivity plots for $\mathrm{SWE}_{\max }$ change with respect to seasonal temperature change $\left({ }^{\circ} \mathrm{C}\right)$ and precipitation change $(\%)$ for nine river basins. The results depict 31-year means from 50-member CanRCM4-LE, and the changes are considered relative to the mean of 1961-2000 baseline period

is some evidence of the counteracting influence of precipitation increases, as depicted by almost identical quantile values at $1.0{ }^{\circ} \mathrm{C}, 1.5^{\circ} \mathrm{C}$, and $2.0^{\circ} \mathrm{C}$ GMT changes. However, there are distinct shifts in the quantile values from $2.0{ }^{\circ} \mathrm{C}$ to $4.0{ }^{\circ} \mathrm{C}$. With higher temperature controls in the interior and coastal/southern basins, the shifts in $\mathrm{SWE}_{\max }$ quantiles are increasingly larger. Consequently, the levels of warming at which majority of years are under SD conditions vary across the region. Specifically, for the Peace, Athabasca, and Saskatchewan basins, SD conditions prevail for majority of years $(>50 \%)$ when the GMT increase reaches $3.0^{\circ} \mathrm{C}$. The levels of warming at which majority of years are under SD conditions are $1.5^{\circ} \mathrm{C}$ for Skeena and Fraser, and $1.0^{\circ} \mathrm{C}$ for Columbia. For Yukon, Peel, and Liard, majority of years do not reach SD conditions even at $4.0{ }^{\circ} \mathrm{C}$ GMT change.

Classifying $\mathrm{SWE}_{\max }$ quantiles into three categories-above-normal, near-normal, and below-normal - depict highly varied responses across the region (Fig. 7). For the Yukon, Peel, and Liard basins, the below-normal conditions are less than the expected occurrences $(33 \%)$, except for $\geq 3.0{ }^{\circ} \mathrm{C}$ GMT change in Yukon and Liard. For rest of the region, however, the SD conditions are greater than expected for all GMT changes including $1.0{ }^{\circ} \mathrm{C}$. Further, for the 
Peace, Athabasca, and Saskatchewan basins, the mean frequencies of SD occurrences are projected to increase from about $40 \%$ at $1.5{ }^{\circ} \mathrm{C}$ to about $45 \%$ at $2.0{ }^{\circ} \mathrm{C}$, and $80 \%$ at $4.0^{\circ} \mathrm{C}$ GMT change. In the case of Skeena, Fraser, and Columbia, the mean SD frequencies are about $60 \%$ at $1.5{ }^{\circ} \mathrm{C}, 75 \%$ at $2.0{ }^{\circ} \mathrm{C}$, and almost $100 \%$ at $4.0^{\circ} \mathrm{C}$ GMT change.

Figure 8 summarizes the below-normal $\mathrm{SWE}_{\max }$ conditions in terms of three SD classes:

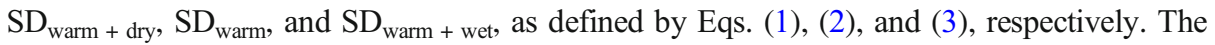
results show that $\mathrm{SD}_{\text {warm + wet }}$ is the dominant class across the region, which is an expected outcome of the future warming and wetting. $\mathrm{SD}_{\text {warm }}$ and $\mathrm{SD}_{\text {warm }}+$ dry occur less frequently because near-normal or below-normal precipitation is less common in a warmer climate. Also note that results for $\mathrm{SD}_{\text {warm }}$ and $\mathrm{SD}_{\text {warm }}+$ dry classes have high uncertainties as the ranges CanRCM4-LE internal variability (as expressed by 50 ensemble members, shown by whiskers) are greater than the mean values for majority of outputs. In the case of $\mathrm{SD}_{\text {warm + wet, the outputs }}$ have greater confidence because the mean values are generally higher than the ranges obtained from the internal variability of CanRCM4-LE. Considering the variability across the region, SD occurrences are more frequent in the warmer coastal/southern basins than the northern basins, again emphasizing the role of temperature control on $\mathrm{SWE}_{\max }$. Thus, the higher the temperature controls, the higher are the SD frequencies with GMT increases. Conversely, the lower temperature controls on $\mathrm{SWE}_{\max }$ in the colder northern basins will make the SD conditions less likely (except for $3.0^{\circ} \mathrm{C}$ or higher GMT change).

The severity of $\mathrm{SD}$ - expressed in terms of remaining $\mathrm{SWE}_{\max }$ percentage relative to the 33rd percentile - indicates small reductions for the northern basins, gradual reductions for the interior basins, and substantial reductions for the coastal/southern basins, with larger changes at higher GMT increases (Fig. 9). Specifically, the remaining $\mathrm{SWE}_{\max }$ for the three SD classes are in the order of $\sim 80 \%$ at $1.5{ }^{\circ} \mathrm{C}$ GMT change, and $\sim 60 \%$ at $4.0{ }^{\circ} \mathrm{C}$ for the interior basins compared to the 33rd percentile of the baseline. In the case of the coastal/ southern basins, the corresponding reductions are $\sim 75 \%$ and $\sim 40 \%$, respectively. Note that these values are only based on SD classes and are different from $\mathrm{SWE}_{\max }$ losses in Fig. 3, where changes relative to the mean $\mathrm{SWE}_{\max }$ for all years (regardless of SD occurrence) were considered. Again, the severity of SD occurrences, e.g., more severe SD in the southern/coastal regions, can be linked to the predominant temperature control. As expected, the reduction in $\mathrm{SWE}_{\max }$, thus the severity of $\mathrm{SD}$, are greater with decreased wetness, i.e., progressively larger $\mathrm{SWE}_{\max }$ reductions from $\mathrm{SD}_{\mathrm{warm}+\text { wet }}$ to $\mathrm{SD}_{\text {warm }}$, and to $\mathrm{SD}_{\mathrm{warm}+}$ dry. Hence, although $\mathrm{SWE}_{\max }$ change is primarily a temperature-controlled process (Fig. 4), precipitation change does play an important role in amplifying or reducing the effect of temperature-driven $\mathrm{SWE}_{\max }$ loss.

Thus, under $1.0^{\circ} \mathrm{C}$ to $4.0^{\circ} \mathrm{C}$ global warming thresholds, areas in the southern NWNA are projected to experience progressively larger declines in snowpack storage leading to predominant SD conditions. The severity and frequencies of SD are most extreme in the Columbia and Fraser basins, where water demands derived primarily from snowmelt-driven runoff, are currently the highest. Furthermore, the basins in the interior regions, i.e., Peace, Athabasca, and Saskatchewan, also have substantial water demand, and are projected to experience SD conditions when GMT increases are $3.0{ }^{\circ} \mathrm{C}$ or higher. Additionally, there are considerable differences in SD severity and frequency between $1.5^{\circ} \mathrm{C}$ and $2.0^{\circ} \mathrm{C}$ for the coastal/southern basins and large differences between $2.0{ }^{\circ} \mathrm{C}$ and $3.0{ }^{\circ} \mathrm{C}$ for the coastal/southern basins and interior basins. Thus, the differences in impacts will be substantially less if the GMT increase were to be limited to $1.5^{\circ} \mathrm{C}$. 

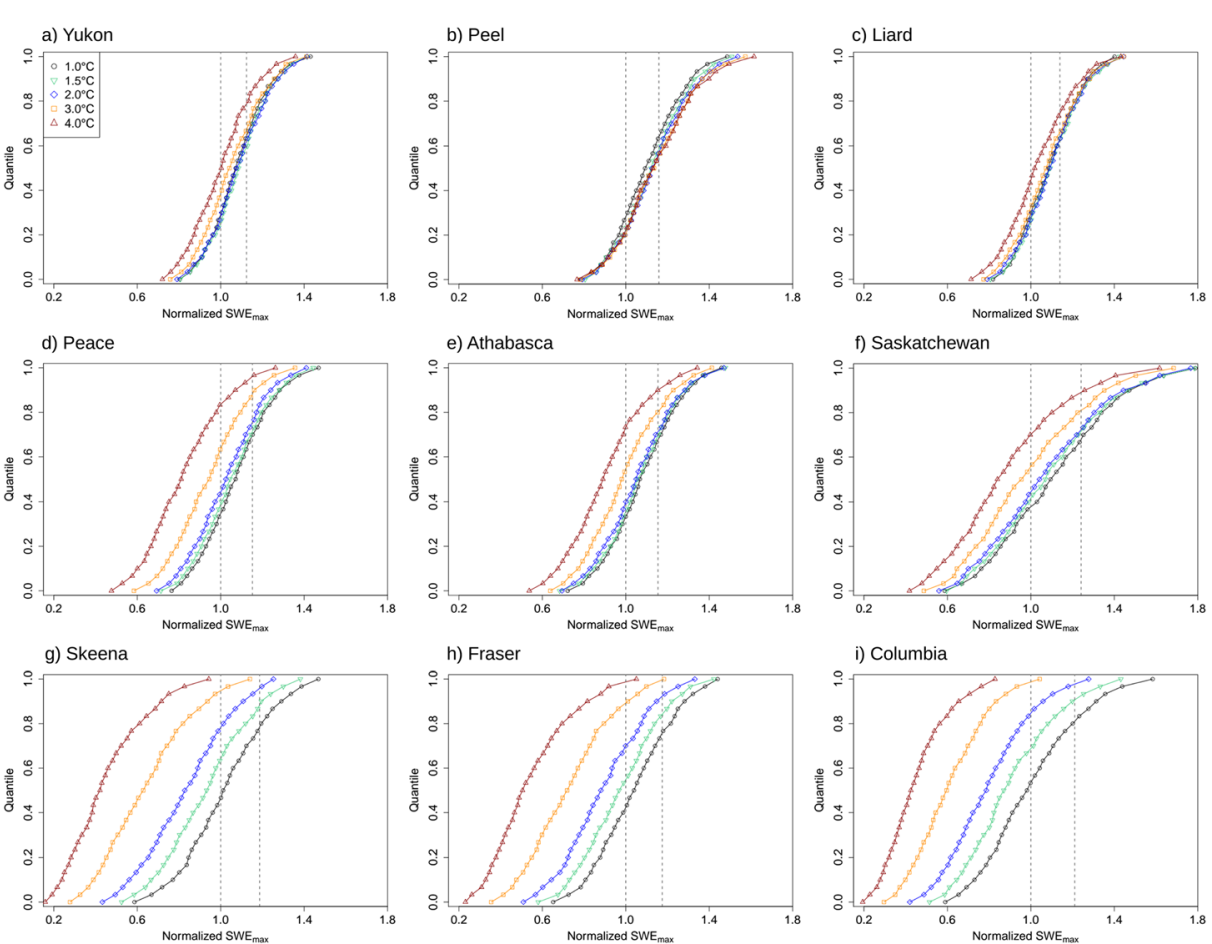

Fig. 6 Changes in the mean of CanRCM4-LE SWE $\max$ quantiles for nine river basins under $1.0{ }^{\circ} \mathrm{C}$ to $4.0{ }^{\circ} \mathrm{C}$ GMT change. The $\mathrm{SWE}_{\max }$ values are normalized by the 33rd percentile of the 1961-2000 baseline period (shown by a vertical line). Second vertical line depict the 67 th percentile

\subsection{Evaluation of CanRCM4-LE simulations}

We evaluated the historical CanRCM4-LE simulation of temperature, precipitation, and SWE by comparing with available snow pillow observations and reanalysis snow data product. These datasets are summarized in SM Table S3, and comparison results are described in detail in SM Section S2. In summary, while CanRCM4 is able to capture some patterns of the observations, there are biases in SWE simulations attributable to mismatch of location and elevation of the point observation with the coarse resolution model grid and uncertainties in SWE simulation by CLASS model. Overall, the limited number of point observations and uncertainties in the data products make it difficult to assess the reliability of CanRCM4 simulations and conduct basin-scale SD analysis using observations.

Comparing the results with VIC simulations for Liard, Peace, and Fraser basins (SM Figs. S7S10), although the directions of changes are consistent, there are differences in the magnitudes, especially for the Fraser basin (e.g., SD frequencies are smaller for VIC at higher GMT changes). The differences arise from a number of factors, including differences in the snow model algorithm in VIC and CLASS (in CanRCM4), model resolution (VIC: 0.0625 ; CanRCM4-LE: 0.44 ), driving GCM structure and their internal variability, and different generations of GCMs (Fraser and Peace VIC simulations are from CMIP3 GCMs), and biases in driving temperature and precipitation. However, the distribution of $\mathrm{SWE}_{\max }$ classes, SD frequency, and severity obtained from CanRCM4LE (Figs. 7, 8, and 9) are generally consistent with those from $0.22^{\circ}$ RCM-ensemble (SM Figs. 

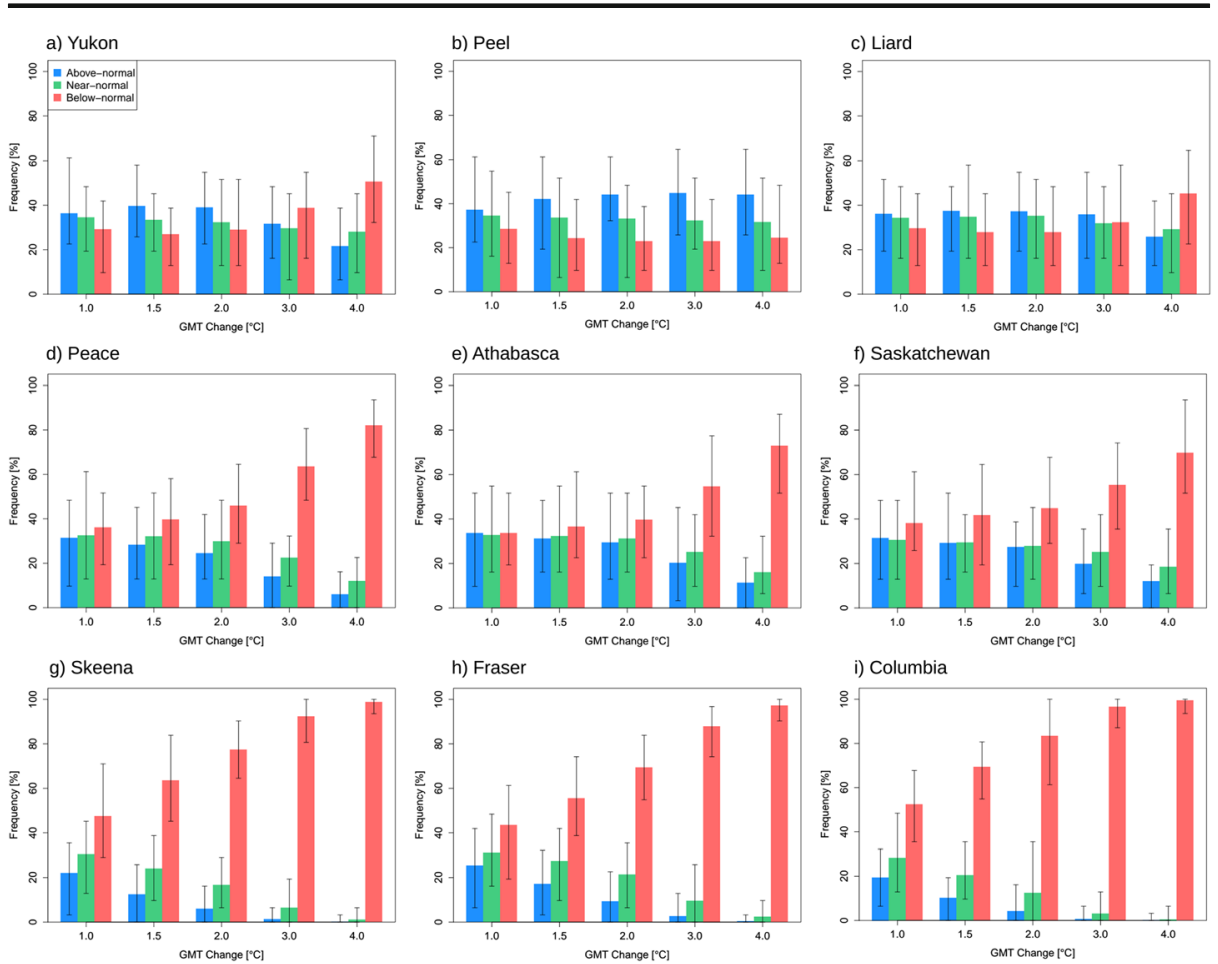

Fig. 7 Frequencies of the three categorical $\mathrm{SWE}_{\max }$ classes: above-normal ( $>67$ th percentile), near-normal (between 33rd and 67th percentiles), and below-normal (<33rd percentile) with respect to the baseline period 1961-2000 under $1.0^{\circ} \mathrm{C}$ to $4.0^{\circ} \mathrm{C}$ GMT change. The frequencies signify percentage occurrences of each $\mathrm{SWE}_{\max }$ class, with $33 \%$ occurrence under baseline and no-change future conditions. The bars depict mean frequencies for the three $\mathrm{SWE}_{\max }$ classes and whiskers depict maximum-minimum range over 50-member ensemble

S11-S13) at different GMT thresholds. The uncertainty range obtained from the internal variability of CanRCM4 also covers the ranges of the RCM-ensemble driven by four GCMs. Overall, despite some differences in magnitudes, the general consistency in the directions of change amongst CanRCM4-LE, RCM-ensemble and VIC results indicate the robustness of CanRCM4-LE for analyzing basin-scale responses.

\section{Summary and conclusions}

This study provided an assessment of snowpack changes for large river basins over the northwestern North America region that span a range of hydro-climatic conditions. Further, by applying the RF machine learning model, and defining SD in a categorical framework, we provided novel perspectives on climatic controls on snowpack changes and snow drought occurrences. Additionally, by using the large ensemble of CanRCM4 simulations under $1.0^{\circ} \mathrm{C}$ to $4.0^{\circ} \mathrm{C}$ GMT increases above the PI period, the study provided a snapshot of basin-scale snowpack changes with respect to IPCCs policy-relevant goals.

The results indicate substantial declines in $\mathrm{SWE}_{\max }$ in the coastal/southern basins (i.e., Skeena, Fraser, and Columbia), moderate decline in the interior basins (i.e., Athabasca, Peace, and Saskatchewan), and marginal increase or decrease in the northern basins (i.e., Yukon, Peel, 

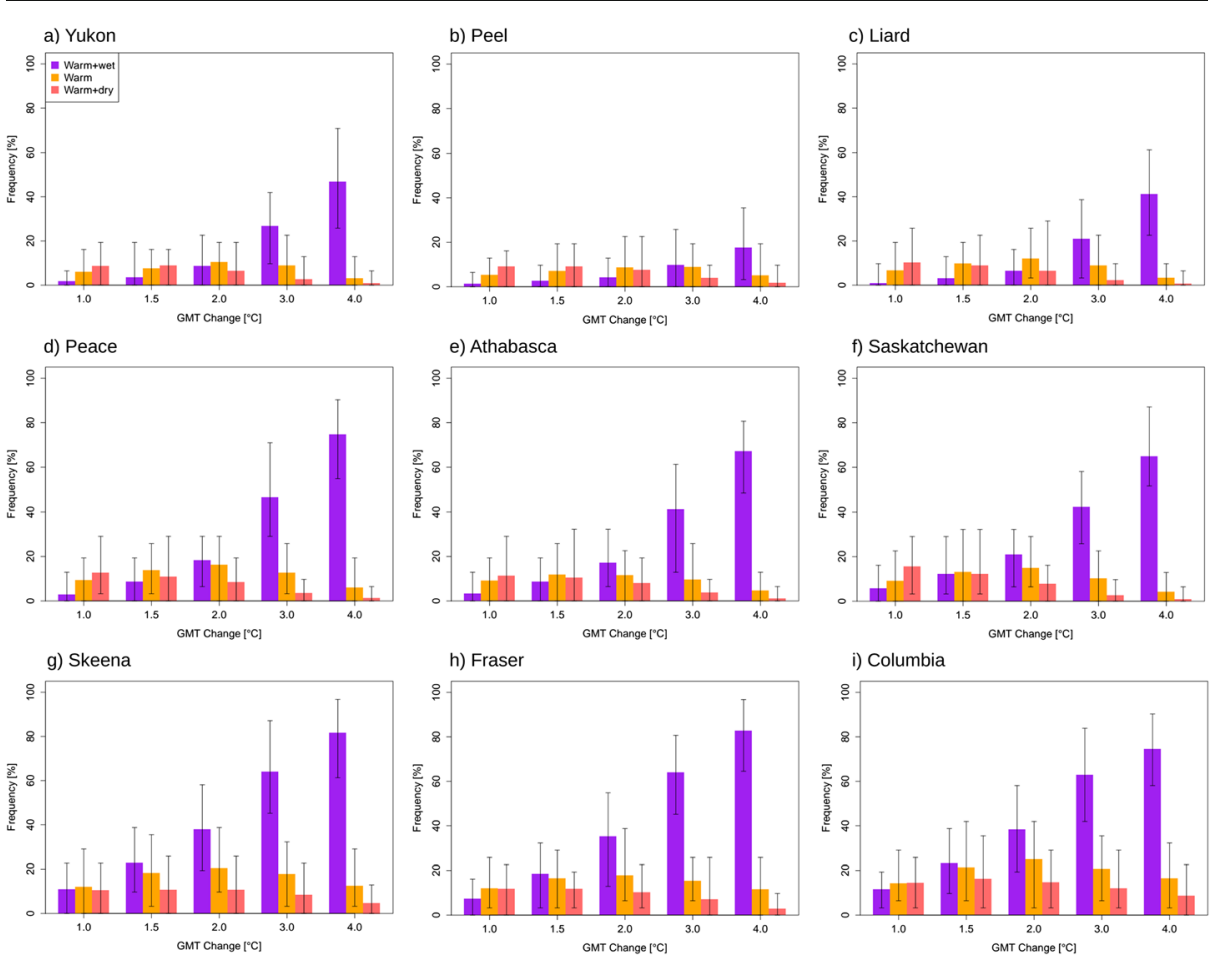

Fig. 8 SD frequencies for below-normal $\mathrm{SWE}_{\max }$ conditions with respect to baseline period 1961-2000 under $1.0^{\circ} \mathrm{C}$ to $4.0^{\circ} \mathrm{C}$ GMT change. The bars depict mean frequencies for three main driving climatic classes (warm + dry; warm and warm + wet) and whiskers maximum-minimum ranges over 50-member ensemble

and Liard), with more contrasting differences under higher warming thresholds. We find that $\mathrm{SWE}_{\max }$ change is primarily temperature controlled, especially for the coastal/southern basins, with the influence of precipitation increasing in the north. An important factor for these differences is the basin-scale mean temperature state, particularly a proximity to the freeze/ melt threshold, with higher $\mathrm{SWE}_{\max }$ losses for basins closer to the threshold.

Using the categorical framework of below-normal, near-normal, and above-normal seasonal temperature, precipitation and annual $\mathrm{SWE}_{\max }$ to define $\mathrm{SD}$ revealed that $\mathrm{SD}$ primarily occurs under above-normal temperature and precipitation. Although SD occurrence under above-normal precipitation may appear counter-intuitive, such a condition implies that precipitation increase cannot compensate the temperature-driven decline in snowpack. However, precipitation change does play a role in amplifying or reducing the effect of temperature-driven SWE loss. Overall, there are considerable differences in SD severity and frequency amongst $1.5^{\circ} \mathrm{C}, 2.0^{\circ} \mathrm{C}$, and $3.0^{\circ} \mathrm{C}$; thus, the differences in impacts will be substantially less if the GMT increase were to be limited to $1.5^{\circ} \mathrm{C}$. The changes in snowpack storage in NWNA will have implications on future water availability in the region. The projected snowpack loss is highest, and SD occurrence is more frequent in the coastal/southern basins, i.e., Columbia and Fraser, where current water demands are the highest. Given that the snowpack loss is accompanied by earlier peak flow and increased winter flow (e.g., Shrestha et al. 2012; Schnorbus et al. 2014), the future water resource management in these coastal/southern basins could be impacted. 

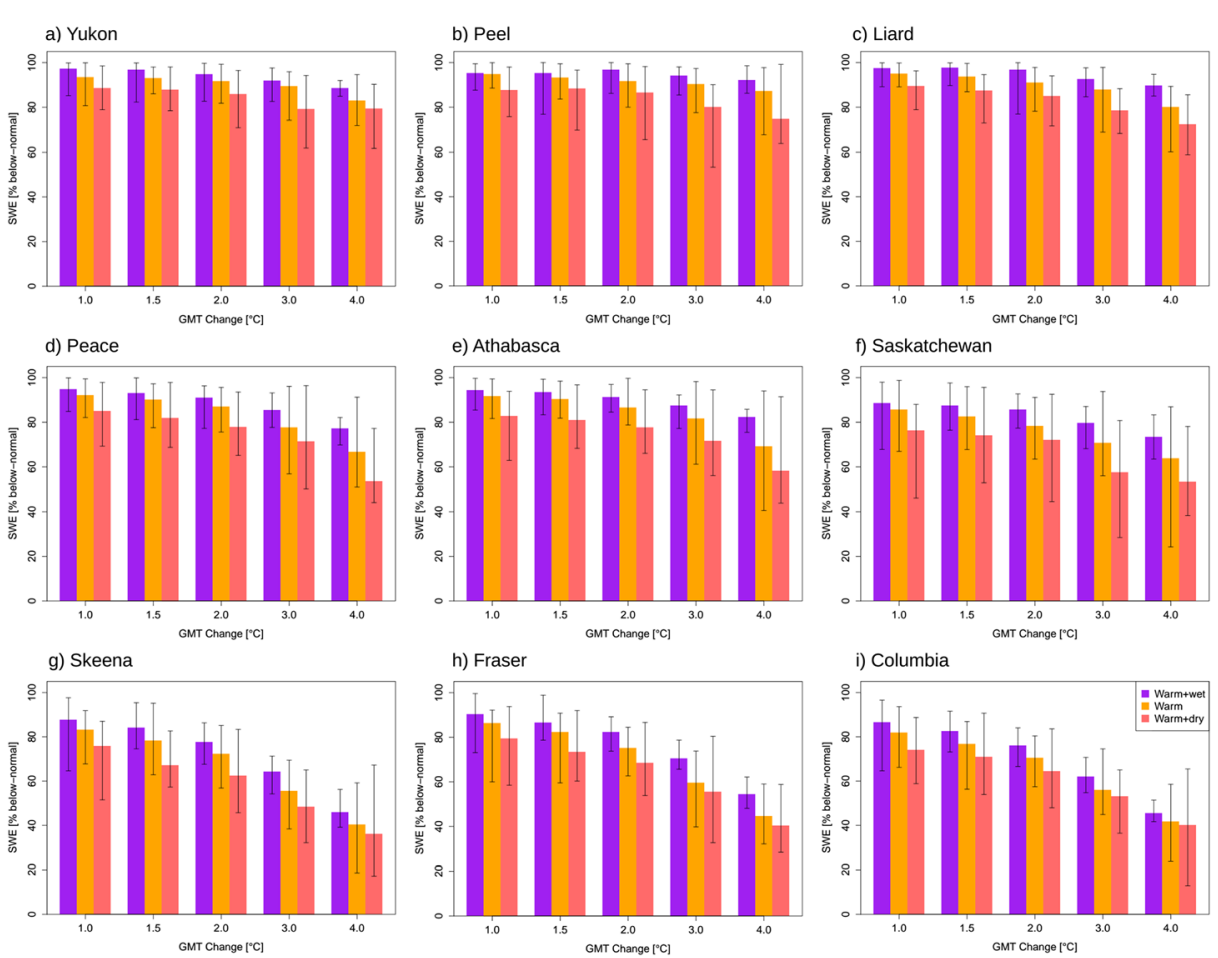

Fig. $9 \mathrm{SD}$ severity expressed in terms of $\% \mathrm{SWE}_{\max }$ remaining relative to the $33 \mathrm{rd}$ percentile of the baseline period $1961-2000$ under $1.0^{\circ} \mathrm{C}$ to $4.0^{\circ} \mathrm{C}$ GMT change. The bars depict mean frequencies for three main driving climatic classes (warm + dry, warm, and warm + wet) and whiskers maximum-minimum ranges over 50-member ensemble

An important issue not considered in this study is the elevation effect on snowpack storage, and the shift in freeze/melt threshold along with the center of mass of snowpack (e.g., Huning \& AghaKouchak, 2018). It was assumed that the resolution effect is not critical for basin-averaged responses, which is supported by general consistency of CanRCM4-LE results with the higher-resolution RCM-ensemble and VIC model results. Nevertheless, the development of fine resolution snow and hydrologic models needs to be prioritized for future research, especially in areas with high elevation gradient and potentially large snowpack loss.

Overall, the insights from this study on snowpack changes, their climatic controls, and interactions with basin-scale mean temperature state, are applicable over wider snowdominated regions spanning a range of hydro-climatological conditions. Additionally, the categorical SD classification methodology developed in this study has a wider applicability for analyzing SD occurrences in a warming climate.

Supplementary Information The online version contains supplementary material available at https://doi.org/ 10.1007/s10584-021-02968-7.

Acknowledgments We thank the Canadian Centre for Climate Modeling and Analysis, Environment and Climate Change Canada for providing the large ensemble CanRCM4 simulations. We thank three anonymous reviewers for their comments, which led to an improved version of the manuscript. 
Author contributions R.R.S., B.R.B., and A.J.C. conceptualized this study. R.R.S. and J.M.B. conducted analyses and produced the figures. R.R.S. wrote the manuscript draft and M.R.N. helped in refining it to the current form. B.R.B., A.J.C., and J.M.B. contributed to edits and revisions.

Funding This study was conducted with internal funding from Environment and Climate Change Canada.

Data availability Original CanRCM4-LE data used in this study are available through the Government of Canada Open Data portal at https:/open.canada.ca/data/en/dataset/83aa1b18-6616-405e-9bce-af7ef8c2031c. Extracted data for individual river basins are available at https://open.canada.ca/data/en/dataset/f8996696-4354471d-808e-f681fa0091b2.

\section{Compliance with ethical standards}

Ethical approval Not applicable.

Consent to participate Not applicable.

Consent to publish Not applicable.

Competing interests The authors declare that they have no competing interests.

Open Access This article is licensed under a Creative Commons Attribution 4.0 International License, which permits use, sharing, adaptation, distribution and reproduction in any medium or format, as long as you give appropriate credit to the original author(s) and the source, provide a link to the Creative Commons licence, and indicate if changes were made. The images or other third party material in this article are included in the article's Creative Commons licence, unless indicated otherwise in a credit line to the material. If material is not included in the article's Creative Commons licence and your intended use is not permitted by statutory regulation or exceeds the permitted use, you will need to obtain permission directly from the copyright holder. To view a copy of this licence, visit http://creativecommons.org/licenses/by/4.0/.

\section{References}

Arora VK, Scinocca JF, Boer GJ et al (2011) Carbon emission limits required to satisfy future representative concentration pathways of greenhouse gases. Geophys Res Lett 38:L05805. https://doi.org/10.1029/ $2010 \mathrm{gl046270}$

Bach AF, van der Schrier G, Melsen LA et al (2018) Widespread and accelerated decrease of observed mean and extreme snow depth over Europe. Geophys Res Lett 45:12,312-12,319. https://doi.org/10.1029/ 2018GL079799

Barnett TP, Adam JC, Lettenmaier DP (2005) Potential impacts of a warming climate on water availability in snow-dominated regions. Nature 438:303-309. https://doi.org/10.1038/nature04141

Barnston AG, Tippett MK (2014) Climate information, outlooks, and understanding-where does the IRI stand? Earth Persp 1:20

Bartlett PA, MacKay MD, Verseghy DL (2006) Modified snow algorithms in the Canadian land surface scheme: model runs and sensitivity analysis at three boreal forest stands. Atmos-Ocean 44:207-222. https://doi.org/ $10.3137 /$ ao. 440301

Beacham TD, Cox-Rogers S, MacConnachie C et al (2014) Population structure and run timing of sockeye salmon in the Skeena River, British Columbia. N Am J Fish Manag 34:335-348

Blöschl G, Hall J, Parajka J et al (2017) Changing climate shifts timing of European floods. Science 357:588590. https://doi.org/10.1126/science.aan2506

Bonsal B, Shrestha RR, Dibike Y, et al (2020) Western Canadian freshwater Availability: Current and Future Vulnerabilities. Environ Rev. https://doi.org/10.1139/er-2020-0040

Breiman L (2001) Random forests. Mach Learn 45:5-32. https://doi.org/10.1023/A:1010933404324

Brown R, Mote P (2009) The response of northern hemisphere snow cover to a changing climate. J Clim 22 : 2124-2145. https://doi.org/10.1175/2008JCLI2665.1 
Bruneau J, Corkal DR, Pietroniro E et al (2009) Human activities and water use in the South Saskatchewan River basin. Prairie Forum, In, pp 129-152

Cohen J, Screen JA, Furtado JC et al (2014) Recent Arctic amplification and extreme mid-latitude weather. Nat Geosci 7:627-637. https://doi.org/10.1038/ngeo2234

Cooper MG, Nolin AW, Safeeq M (2016) Testing the recent snow drought as an analog for climate warming sensitivity of cascades snowpacks. Environ Res Lett 11:084009. https://doi.org/10.1088/1748-9326/11/8/ 084009

Derksen C, Brown R, Mudryk L, Luojus K (2015) Arctic: terrestrial snow. State of the Climate in 2014. J. Blunden and D. S. Arndt. Bull Am Meteorol Soc 96:133-135

Deser C, Lehner F, Rodgers KB et al (2020) Insights from earth system model initial-condition large ensembles and future prospects. Nat Clim Chang 10:277-286. https://doi.org/10.1038/s41558-020-0731-2

Dibike Y, Eum H-I, Prowse T (2018) Modelling the Athabasca watershed snow response to a changing climate. J Hydrol: Reg Stud 15:134-148. https://doi.org/10.1016/j.ejrh.2018.01.003

Dierauer JR, Allen DM, Whitfield PH (2019) Snow drought risk and susceptibility in the Western United States and southwestern Canada. Water Resour Res 55:3076-3091. https://doi.org/10.1029/2018WR023229

Diffenbaugh NS, Scherer M, Ashfaq M (2013) Response of snow-dependent hydrologic extremes to continued global warming. Nat Clim Chang 3:379-384. https://doi.org/10.1038/nclimate1732

Dudley RW, Hodgkins GA, McHale MR et al (2017) Trends in snowmelt-related streamflow timing in the conterminous United States. J Hydrol 547:208-221. https://doi.org/10.1016/j.jhydrol.2017.01.051

Eliason EJ, Clark TD, Hague MJ et al (2011) Differences in thermal tolerance among sockeye salmon populations. Science 332:109-112. https://doi.org/10.1126/science.1199158

Ficklin DL, Stewart IT, Maurer EP (2013) Effects of climate change on stream temperature, dissolved oxygen, and sediment concentration in the Sierra Nevada in California. Water Resour Res 49:2765-2782

Fyfe JC, Derksen C, Mudryk L et al (2017) Large near-term projected snowpack loss over the western United States. Nat Commun 8:14996. https://doi.org/10.1038/ncomms14996

Gergel DR, Nijssen B, Abatzoglou JT et al (2017) Effects of climate change on snowpack and fire potential in the western USA. Clim Chang:1-13. https://doi.org/10.1007/s10584-017-1899-y

Hamlet AF, Huppert D, Lettenmaier DP (2002) Economic value of long-lead streamflow forecasts for Columbia River hydropower. J Water Resour Plan Manag 128:91-101. https://doi.org/10.1061/(ASCE)07339496(2002)128:2(91)

Harpold AA, Dettinger M, Rajagopal S (2017) Defining snow drought and why it matters. EOS 98. https://doi. org/10.1029/2017EO068775

Hatchett BJ, McEvoy DJ (2017) Exploring the origins of snow drought in the northern Sierra Nevada, California. Earth Interact 22:1-13. https://doi.org/10.1175/EI-D-17-0027.1

Huning LS, AghaKouchak A (2018) Mountain snowpack response to different levels of warming. PNAS 115: 10932-10937. https://doi.org/10.1073/pnas.1805953115

Instanes A, Kokorev V, Janowicz R et al (2016) Changes to freshwater systems affecting Arctic infrastructure and natural resources. J Geophys Res Biogeosci 121:567-585. https://doi.org/10. 1002/2015JG003125

IPCC (2018) Summary for policymakers. In: Global Warming of $1.5^{\circ} \mathrm{C}$. An IPCC Special Report on the impacts of global warming of $1.5^{\circ} \mathrm{C}$ above pre-industrial levels and related global greenhouse gas emission pathways, in the context of strengthening the global response to the threat of climate change, sustainable development, and efforts to eradicate poverty. World Meteorological Organization, Geneva, Switzerland

Jacob D, Elizalde A, Haensler A et al (2012) Assessing the transferability of the regional climate model REMO to Different COordinated Regional Climate Downscaling EXperiment (CORDEX) regions. Atmos 3:181199. https://doi.org/10.3390/atmos3010181

Jeong DI, Cannon AJ, Zhang X (2019) Projected changes to extreme freezing precipitation and design ice loads over North America based on a large ensemble of Canadian regional climate model simulations. Nat Haz Earth Syst Sci 19:857-872. https://doi.org/10.5194/nhess-19-857-2019

Kay JE, Deser C, Phillips A et al (2015) The Community Earth System Model (CESM) large ensemble project: a community resource for studying climate change in the presence of internal climate variability. Bull Amer Meteor Soc 96:1333-1349. https://doi.org/10.1175/BAMS-D-13-00255.1

Kirchmeier-Young MC, Zwiers FW, Gillett NP (2017) Attribution of extreme events in Arctic sea ice extent. J Clim 30:553-571

Liaw A, Wiener M (2018) randomForest: Breiman and Cutler's random forests for classification and regression. Version 4.6-14URL https:/CRAN.R-project.org/package=randomForest

Liaw A, Wiener M (2002) Classification and regression by randomForest. R news 2:18-22

Luce CH, Lopez-Burgos V, Holden Z (2014) Sensitivity of snowpack storage to precipitation and temperature using spatial and temporal analog models. Water Resour Res 50:9447-9462. https://doi.org/10.1002/ 2013WR014844 
Lute AC, Luce CH (2017) Are model transferability and complexity antithetical? Insights from validation of a variable-complexity empirical snow model in space and time. Water Resour Res 53:8825-8850. https://doi. org/10.1002/2017WR020752

Marshall AM, Abatzoglou JT, Link TE, Tennant CJ (2019) Projected changes in interannual variability of peak snowpack amount and timing in the Western United States. Geophy Res Lett 46:8882-8892. https://doi.org/ 10.1029/2019GL083770

Millar CI, Stephenson NL (2015) Temperate forest health in an era of emerging megadisturbance. Science 349: 823-826. https://doi.org/10.1126/science.aaa9933

Min S-K, Zhang X, Zwiers F (2008) Human-induced Arctic moistening. Science 320:518-520. https://doi.org/ 10.1126/science. 1153468

Morrison J, Quick MC, Foreman MG (2002) Climate change in the Fraser River watershed: flow and temperature projections. J Hydrol 263:230-244. https://doi.org/10.1016/S0022-1694(02)00065-3

Mote PW, Li S, Lettenmaier DP, et al (2018) Dramatic declines in snowpack in the western US npj Clim Atmos Sci 1:1-6. https://doi.org/10.1038/s41612-018-0012-1

Mote PW, Rupp DE, Li S et al (2016) Perspectives on the causes of exceptionally low 2015 snowpack in the western United States. Geophys Res Lett 43:10,980-10,988. https://doi.org/10.1002/2016GL069965

Mudryk LR, Derksen C, Howell S et al (2018) Canadian snow and sea ice: historical trends and projections. Cryos 12:1157-1176. https://doi.org/10.5194/tc-12-1157-2018

Najafi MR, Zwiers F, Gillett N (2017) Attribution of the observed spring snowpack decline in British Columbia to anthropogenic climate change. J Clim 30:4113-4130. https://doi.org/10.1175/JCLI-D-16-0189.1

Nolin AW, Daly C (2006) Mapping "at risk" snow in the Pacific northwest. J Hydrometeorol 7:1164-1171. https://doi.org/10.1175/JHM543.1

O'Gorman PA (2014) Contrasting responses of mean and extreme snowfall to climate change. Nature 512:416418. https://doi.org/10.1038/nature13625

Pierce DW, Barnett TP, Hidalgo HG et al (2008) Attribution of declining Western U.S. snowpack to human effects. J Clim 21:6425-6444. https://doi.org/10.1175/2008JCLI2405.1

Pomeroy JW, Fang X, Marks DG (2016) The cold rain-on-snow event of June 2013 in the Canadian Rockies characteristics and diagnosis. Hydrol Process 30:2899-2914. https://doi.org/10.1002/hyp.10905

Räisänen J (2008) Warmer climate: less or more snow? Clim Dyn 30:307-319. https://doi.org/10.1007/s00382007-0289-y

Schleussner C-F, Lissner TK, Fischer EM et al (2016) Differential climate impacts for policy-relevant limits to global warming: the case of 1.5 \&deg;C and 2 \&deg;C. Earth Syst Dyn 7:327-351. https://doi.org/10.5194/ esd-7-327-2016

Schnorbus M, Werner A, Bennett K (2014) Impacts of climate change in three hydrologic regimes in British Columbia, Canada. Hydrol Process 28:1170-1189. https://doi.org/10.1002/hyp.9661

Scinocca JF, Kharin VV, Jiao Y et al (2015) Coordinated global and regional climate modeling. J Clim 29:1735. https://doi.org/10.1175/JCLI-D-15-0161.1

Serreze MC, Barry RG (2011) Processes and impacts of Arctic amplification: a research synthesis. Glob Planet Chang 77:85-96. https://doi.org/10.1016/j.gloplacha.2011.03.004

Shrestha RR, Cannon AJ, Schnorbus MA, Alford H (2019) Climatic controls on future hydrologic changes in a subarctic river basin in Canada. J Hydrometeorol. https://doi.org/10.1175/JHM-D-18-0262.1

Shrestha RR, Cannon AJ, Schnorbus MA, Zwiers FW (2017) Projecting future nonstationary extreme streamflow for the Fraser River, Canada. Clim Chang:1-15. https://oi.org/10.1007/s10584-017-2098-6

Shrestha RR, Schnorbus MA, Werner AT, Berland AJ (2012) Modelling spatial and temporal variability of hydrologic impacts of climate change in the Fraser River basin, British Columbia, Canada. Hydrol Process 26:1840-1860. https://doi.org/10.1002/hyp.9283

Sospedra-Alfonso R, Merryfield WJ (2017) Influences of temperature and precipitation on historical and future snowpack variability over the northern hemisphere in the second generation Canadian earth system model. J Clim 30:4633-4656. https://doi.org/10.1175/JCLI-D-16-0612.1

Sturm M, Goldstein MA, Parr C (2017) Water and life from snow: a trillion dollar science question. Water Resour Res 53:3534-3544. https://doi.org/10.1002/2017WR020840

Taylor KE, Stouffer RJ, Meehl GA (2012) An overview of CMIP5 and the experiment design. Bull Am Meteor Soc 93:485-498. https://doi.org/10.1175/BAMS-D-11-00094.1

Trujillo E, Molotch NP, Goulden ML et al (2012) Elevation-dependent influence of snow accumulation on forest greening. Nat Geosci 5:705-709 
Verseghy DL (2000) The Canadian land surface scheme (CLASS): its history and future. Atmos-Ocean 38:1-13. https://doi.org/10.1080/07055900.2000.9649637

Von Salzen K, Scinocca JF, McFarlane NA et al (2013) The Canadian fourth generation atmospheric global climate model (CanAM4). Part I: representation of physical processes Atmos-Ocean 51:104-125

Wang Z, Lai C, Chen X et al (2015) Flood hazard risk assessment model based on random forest. J Hydrol 527: 1130-1141. https://doi.org/10.1016/j.jhydrol.2015.06.008

Zhang X, He J, Zhang J et al (2013) Enhanced poleward moisture transport and amplified northern high-latitude wetting trend. Nat Clim Chang 3:47-51. https://doi.org/10.1038/nclimate1631

Publisher's note Springer Nature remains neutral with regard to jurisdictional claims in published maps and institutional affiliations.

\section{Affiliations}

\section{Rajesh R. Shrestha ${ }^{1} \cdot$ Barrie R. Bonsal $^{2}$ • James M. Bonnyman ${ }^{1}$ • Alex J. Cannon ${ }^{3} \cdot$ Mohammad Reza Najafi $^{4}$}

1 Watershed Hydrology and Ecology Research Division, Environment and Climate Change Canada, University of Victoria, Victoria, BC, Canada

2 Watershed Hydrology and Ecology Research Division, Environment and Climate Change Canada, Saskatoon, SK, Canada

3 Climate Research Division, Environment and Climate Change Canada, University of Victoria, Victoria, BC, Canada

4 Department of Civil and Environmental Engineering, Western University, London, ON, Canada 